\title{
Ação moduladora da microbiota de portadores de síndrome de Down sobre bactérias cariogênicas
}

\author{
Marina Dórea de Almeida ${ }^{1}$ \\ Mônica Pereira Franca ${ }^{2}$ \\ Lilia Ferreira de Moura Costa ${ }^{3}$ \\ Bárbara Laisa Alves Moura ${ }^{3}$ \\ Urbino da Rocha Tunes ${ }^{4}$ \\ Paulo Fernando de Almeidas
}

\begin{abstract}
Resumo
Os portadores da Síndrome de Down possuem baixa prevalência de cárie, apesar de apresentarem uma higiene oral deficiente. O estudo foi realizado para detectar cepas produtoras de bacteriocinas, com o intuito de avaliar a sua possível ação como moduladoras da microbiota cariogênica dos sindrômicos. Streptococcus mutans e Streptococcus sobrinus são os principais produtores de ácidos na cavidade oral. Em função disso, esses estreptococos foram testados antagonicamente com cepas isoladas dos indivíduos com Síndrome de Down, para que fosse avaliado se havia inibição das bactérias cariogênicas pelas cepas dos sindrômicos. Streptococcus mutans e Streptococcus sobrinus foram isolados utilizando o meio ágar sacarose bacitracina e identificados através de provas bioquímicas. Uma amostra de placa supragengival dos sindrômicos foi coletada e semeada por disseminação em Ágar Mitis-Salivarius, após o isolamento foram cultivados em caldo BHI. Dez culturas dos sindrômicos foram semeadas no Ágar Muller Hinton. Após o crescimento, as placas foram tratadas com clorofórmio. Sucessivamente, uma porção das culturas de bactérias cariogênicas foi transferida para meio semi-sólido BHI e vertidas nas placas com as culturas testes. Duas das dez cepas testadas apresentaram halo de inibição de crescimento contra cepas de Streptococcus mutans. A descoberta de cepas que produzem substâncias antimicrobianas pode ser responsável pela baixa prevalência de cárie em indivíduos com Síndrome de Down. Esse achado pode ajudar a entender a relação entre microbiota oral e patologia da cárie dentária.
\end{abstract}

Palavras-chave: Streptococcus mutans; Streptococcus sobrinus; Cárie - Síndrome de Down; Bacteriocinas.

\section{INTRODUÇÃO}

A Síndrome de Down é caracterizada pela trissomia do cromossomo 21, ocorrendo em aproximadamente um a cada setecentos nasci- mentos (AMANO et al., 2000). Estudando as doenças orais destes sindrômicos, observa-se que esses indivíduos possuem uma maior prevalência

\footnotetext{
${ }^{1}$ Bolsista de Iniciação Científica PIBIC-CADCT. Faculdade de Odontologia. UFBA. Salvador - BA

2 Professora Assistente de Microbiologia. Faculdade de Odontologia. FBDC. Salvador - BA

${ }^{3}$ Professora Assistente de Microbiologia. Instituto de Ciências da Saúde. UFBA. Salvador - BA

${ }^{4}$ Acadêmica do Curso de Odontologia. UFBA. Salvador - BA

${ }^{5}$ Professor Titular de Periodontia. Faculdade de Odontologia. FBDC. Salvador - BA

${ }^{6}$ Professor Adjunto de Microbiologia. Instituto de Ciências da Saúde. UFBA. Salvador - BA

Correspondência para / Correspondence to:

Paulo Fernando de Almeida

Departamento de Biointeração

Instituto de Ciências da Saúde - UFBA

Av. Reitor Miguel Calmon, s/n -Vale do Canela.

40.160-100 Salvador -Bahia- Brasil.

Tel.: (71) 3245-8602

E-mail: pfa@ufba.br, www.microbiologia.ufba.br
} 
de doença periodontal que os indivíduos normais; analisando os índices de cáries, observa-se o oposto: os sindrômicos possuem menor prevalência de cáries que os normais. Esse fato é intrigante, pois tais indivíduos possuem dificuldades motoras que dificultam a higienização bucal (SHAPIRA et al., 1991; MORINUSHI; LOPATIN; TANAKA, 1995; PINAZZO; VIANNA, 1998/1999).

A doença periodontal nos sindrômicos é mais precoce que nos indivíduos normais, segundo Amano e colaboradores (2000), os quais sugerem que esse fato se deve a um debilitado sistema imune, um frágil tecido periodontal, ou a um envelhecimento precoce.

Uma explicação para a baixa prevalência de cárie nos portadores de Síndrome de Down pode ser atribuída à presença de agentes moduladores da microbiota da cavidade oral desses indivíduos. Bactérias produtoras de substâncias com ação contra bactérias cariogênicas podem explicar a baixa prevalência de cárie dos sindrômicos.

Azevedo, Zelante e Ito (1985), citando Jacob e colaboradores, definem bacteriocinas como proteínas de elevado peso molecular, elaboradas por bactérias que apresentam espectro de ação antibacteriano limitado a espécies bastante afins às cepas produtoras.

Fantinato, Jorge e Shimizu (1999) acreditam que essa interferência bacteriana é uma proteção natural contra bactérias patogênicas e sugeriram que as cepas produtoras de bacteriocinas podem ser vistas como um instrumento na prevenção de certas doenças.

Para analisar a atividade antimicrobiana das cepas isoladas dos portadores de Síndrome de Down, foi utilizada a técnica de Azevedo, Zelante e Ito (1985), utilizando-se cepas indicadoras da produção de bacteriocina, sendo que, nesta pesquisa, as cepas indicadoras foram as sabidamente cariogênicas: Streptococcus mutans e Streptococcus sobrinus.

A produção de ácidos, principalmente em um $\mathrm{pH}$ diminuído, é determinante da atividade cariogênica de uma cepa. Soet, Nyvad e Kilian (2000) analisaram a velocidade de produção de ácidos de cepas caracterizadas como estreptococos orais do grupo mitis e cepas de Streptococcus mutans e Streptococcus sobrinus. Os resultados demonstraram que, em todos os valores de $\mathrm{pH}$, a velocidade de produção de ácidos do Streptococcus mutans e Streptococcus sobrinus eram significativamente maiores que dos outros estreptococos orais. O Streptococcus sobrinus apresentou-se como o mais acidúrico e acidogênico das espécies testadas.

As espécies de estreptococos do grupo mutans, mais predominantemente isoladas de amostras salivares, são Streptococcus mutans e Streptococcus sobrinus (HÖFLING et al., 1999), sendo que a associação Streptococcus mutans e Streptococcus sobrinus é potencialmente mais cariogênica que a colonização apenas pelo Streptococcus mutans.

O presente trabalho visa à detecção de cepas produtoras de substâncias antimicrobianas como moduladoras da microbiota oral em portadores de Síndrome de Down. Para a realização dos testes, foi necessário o isolamento e identificação da cepas de Streptococcus mutans e Streptococcus sobrinus, o isolamento de microrganismos a partir de amostras de placa bacteriana de portadores de Síndrome de Down e a avaliação da ação antimicrobiana de cepas da microbiota dos sindrômicos contra as bactérias cariogênicas.

\section{MATERIAIS E MÉTODOS}

Isolamento e Identificação de Streptococcus mutans e Streptococcus sobrinus

A amostragem para o isolamento e identificação de cepas de Streptococcus mutans e Streptococcus sobrinus constou de dez crianças, pacientes das disciplinas de Cariologia e de Odontopediatria da Faculdade de Odontologia da Universidade Federal da Bahia, com idade entre três a dez anos, de ambos os sexos, sem distinção de raça ou cor, que foram examinadas no que diz respeito a cáries dentais, seguindo-se orientação de Pinto (1990).

A coleta da placa supragengival foi realizada assepticamente no ambulatório dessas disciplinas, sendo o suabe passado cuidadosa- 
mente pelas superfícies dentais das crianças. $\mathrm{O}$ material contido no suabe foi semeado através do método da estria composta no meio ágar sacarose bacitracina - SB20 (DAVEY; ROGERS, 1984). A coleta em todas as crianças foi realizada em duplicata. As placas foram transportadas para o laboratório e colocadas em jarras com atmosfera reduzida, obtida pela queima de uma vela (TORTORA; FUNKE; CASE, 2000). A incubação foi feita a $37^{\circ} \mathrm{C}$ por quarenta e oito horas.

A observação e a contagem das colônias com características pertencentes aos estreptococos do grupo mutans foram realizadas sob luz artificial, seguindo-se os padrōes descritos para o meio ágar sacarose bacitracina SB20 (DAVEY; ROGERS, 1984).

As colônias, com os tipos morfológicos característicos foram transferidas para tubos com $5,0 \mathrm{ml}$ do meio tioglicolato estéril e incubadas a $37^{\circ} \mathrm{C}$ por vinte e quatro horas, em atmosfera reduzida. As culturas foram submetidas à coloração de Gram e a provas bioquímicas para que fossem isoladas e identificadas como cepas de espécies de Streptococcus mutans e Streptococcus sobrinus.

Isolamento das Cepas de Placa Dental de Portadores de Síndrome de Down

Para o presente estudo, foram selecionados quinze portadores de Síndrome de Down, sem distinção de idade, raça ou cor, de ambos os sexos, alunos da Escola Especializada do SESI (Serviço Social da Indústria), após autorização cedida pela diretoria da escola e consentimento dos pais.

As coletas foram realizadas em um equipo odontológico da própria escola. Com o auxílio de uma cureta dentinária estéril, era coletada placa supragengival de duas superfícies dentais de cada sindrômico. O pool de placa de cada indivíduo era transportado assepticamente para um tubo de microcentrífuga, contendo 1,0 $\mathrm{ml}$ da solução de PBS (Phosphate-buffered saline) estéril, como preconizado por Amano e colaboradores (2000).

Os tubos de microcentrífuga foram levados para o laboratório e as amostras eram agita- das e passavam por diluições decimais sucessivas em solução de PBS, acrescida de Tween 80 , obtendo-se até a diluição $10^{-5}$. Alíquotas de 0,1 $\mathrm{ml}$ das diluições $10^{-3}, 10^{-4} \mathrm{e} 10^{-5}$ foram semeadas por disseminação, com o auxílio de uma alça de Drigalsky estéril, em placas de Petri com o meio de ágar Mitis Salivarius. As placas foram incubadas a $37^{\circ} \mathrm{C}$ por vinte e quatro horas, em atmosfera reduzida.

A observação e a contagem das colônias foram realizadas sob luz artificial e quantificadas através da UFC/ml (unidades formadoras de colônias por mililitro). Os diferentes tipos morfológicos das colônias foram caracterizados.

As colônias que possuíam tipos morfológicos distintos eram transferidas para tubos com 5,0 ml do meio tioglicolato estéril e incubadas a $37^{\circ} \mathrm{C}$ por vinte e quatro horas, em atmosfera reduzida. Após o crescimento bacteriano, os tubos foram conservados em estufa a $22^{\circ} \mathrm{C}$ e repicados a cada quinze dias.

\section{Detecção de Bacteriocinas:}

Para a detecção de substâncias que, in vitro, apresentam propriedades antimicrobianas, foi utilizada a técnica do "antagonismo posposto", já anteriormente adotada por Azevedo, Zelante e Ito (1985); porém a técnica foi modificada pelo tratamento com clorofórmio das placas de Petri após o crescimento das colônias testes e antes da semeadura das cepas indicadoras.

As culturas das cepas-teste, isto é cepas isoladas dos portadores de Síndrome de Down, foram ativadas em caldo tioglicolato a $37^{\circ} \mathrm{C}$, por vinte e quatro horas, em atmosfera reduzida. Posteriormente, alíquotas de $0,01 \mathrm{ml}$ das culturas das cepas a serem testadas como produtoras de bacteriocinas foram semeadas com o auxílio de pipeta automática, no meio Ágar MullerHinton. As placas foram deixadas à temperatura ambiente para a absorção da porção da cultura. Em seguida, foram incubadas a $37^{\circ} \mathrm{C}$ por quarenta e oito horas, em atmosfera reduzida. O crescimento das cepas dos portadores de Síndrome de Down em Agar Muller-Hinton pode ser observado na Figura 1.

Após o crescimento bacteriano, as placas de Petri foram tratadas com clorofórmio. Para 


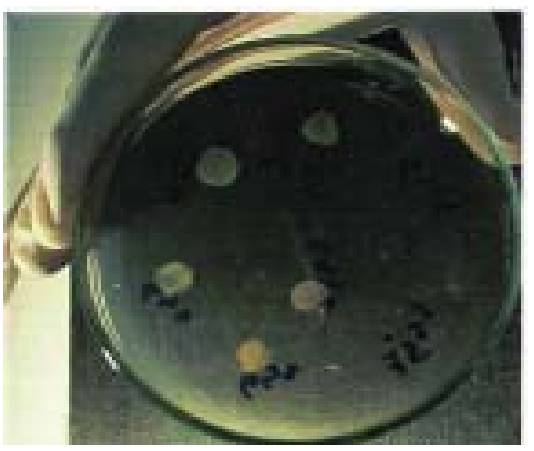

Figura 1 - Cepa de placa supra gengival de indivíduo portador da Sindrome de Down, em Agar Muller-Hinton

isso, as placas foram vertidas em gazes estéreis, umedecidas com $5 \mathrm{ml}$ de clorofórmio e mantidas na parte interna da tampa durante trinta minutos (LIMA et al., 2002).

Duas cepas foram utilizadas como indicadoras da produção de bacteriocina: uma pertencia à espécie de Streptococcus mutans, e outra à Streptococcus sobrinus. Essas cepas foram semeadas em tioglicolato e incubadas a $37^{\circ} \mathrm{C}$, por vinte e quatro horas, em atmosfera reduzida.

Após o crescimento bacteriano, as culturas foram diluídas a 1:10, 1:35 e 1:100, em caldo BHI (Heart Infusion Broth) estéril. Os inóculos

finais foram preparados utilizando-se de BHI semi-sólido, obtendo-se as concentraçôes finais de 1:85, 1:300 e 1:850, respectivamente.

Depois de feitas as diluições em caldo $\mathrm{BHI}$, alíquotas de 1,0 $\mathrm{ml}$ da diluição apropriada da cepa indicadora foram transferidas para 7,5 ml de BHI semi-sólido, mantido a aproximadamente $50^{\circ} \mathrm{C}$. Essa mistura foi homogeneizada e vertida sobre a superfície do ágar previamente semeado com as cepas-teste. As placas foram mantidas à temperatura ambiente até a completa solidificação e posteriormente reincubadas a $37^{\circ} \mathrm{C}$, por vinte e quatro horas, em atmosfera reduzida. O crescimento foi analisado observando-se a formação ou não de halos de inibição de crescimento em volta das colônias-teste (BALAKRISHNAN; SIMMONDS; TAGG, 2001).

As cepas que estimularam algum halo de inibição eram testadas pela produção de catalase e, após a coloração de Gram, eram observadas ao microscópio. Essas cepas foram semeadas em caldo tioglicolato por vinte e quarto horas, a $37^{\circ} \mathrm{C}$, em atmosfera reduzida, e, com as culturas ainda ativas, eram semeadas em ágar sacarose bacitracina e testadas quanto às provas do manitol e sorbitol.

\section{RESULTADOS}

Com os experimentos de isolamento e identificação do Streptococcus mutans e Streptococcus sobrinus, foram obtidos os seguintes resultados: das vinte amostras de placa supragengival, foram isoladas nove colônias com características de Streptococcus mutans e Streptococcus sobrinus. Após a identificação bioquímica, resultaram três cepas de Streptococcus mutans e duas de Streptococcus sobrinus.

Os experimentos para obtenção das cepas-teste resultaram em cinqüenta cepas isoladas de amostras de placa supragengival dos portadores de Síndrome de Down. Porém os testes para observar a possível produção de substâncias antimicrobianas foram feitos com apenas dez dessas cepas, já que muitas eram perdidas durante a ativação no meio tioglicolato, e outras não apresentavam crescimento no ágar Müller Hinton, o que impossibilitava os testes do "antagonismo posposto" com essas cepas.

A leitura dos resultados dos testes para constatação da presença de bacteriocinas foi feita observando-se as zonas ou halos de inibição do crescimento das cepas indicadoras, em torno das colônias das cepas-teste. A pesquisa foi realizada com dez cepas isoladas de portadores de

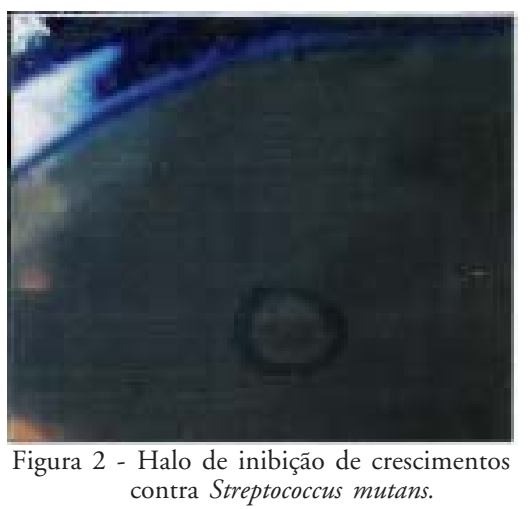

R. Ci. méd. biol., Salvador, v. 4, n. 3, p. 214-220, set./dez. 2005 
Síndrome de Down, sendo cada uma delas testadas contra duas cepas indicadoras (Streptococcus mutans e Streptococcus sobrinus). Das dez cepas testadas, duas apresentaram halo de inibição de crescimento contra Streptococcus mutans de aproximadamente três centímetros de diâmetro (FIGURA 2).

Essas duas colônias que estimularam halo de inibição caracterizaram-se, em ágar Mitis Salivarius, como colônias grandes, claras, translúcidas, semelhantes à gelatina, bastante amolecidas, facilmente removidass do meio, havendo sempre colônias escuras e pequenas abaixo e ao lado delas, ou colônias grandes colunares.

Essas cepas, que inibiram o crescimento de Streptococcus mutans, foram caracterizadas como catalase negativa e como estreptococos.

Por apresentarem crescimento em ágar sacarose bacitracina, as cepas demonstraram ser resistentes à bacitracina e caracterizaram-se como manitol e sorbitol positivas. Com esses resultados, essas duas cepas são sugestivas de pertencerem ao grupo mutans.

\section{DISCUSSÃO}

A técnica do "antagonismo posposto" foi adotada por apresentar a vantagem de permitir a difusão da bacteriocina no meio, antes da semeadura da cepa indicadora, além de possibilitar o estabelecimento de comparação entre os diversos espectros de ação, sob a mesma condição experimental.

A modificação adotada para a técnica do "antagonismo posposto" (AZEVEDO; ZELANTE; ITO, 1985), isto é, o tratamento com clorofórmio das placas com as colônias- teste, antes da semeadura das cepas indicadora, foi realizado para impedir interação e a inibição por competição entre as colônias, o que resultaria em um viés para os resultados obtidos na pesquisa. Assim, as cepas dos portadores de Síndrome de Down foram testadas apenas pela possível presença de substancias antibacterianas em suas colônias.

Em contrapartida, o tratamento com o clorofórmio pode ter influenciado nos resulta- dos obtidos, pois é possível que seja o responsável por desnaturação protéica, tornando inativas as bacteriocinas, que têm composição protéica.

O resultado em questão - apenas duas das cepas testadas apresentaram efeito inibitório -, pode ter sido prejudicado, pois as bactérias que colonizam o periodonto podem ser as responsáveis pela inibição das cepas cariogênicas. Porém, para essas cepas, não foram permitidos os isolamentos e os testes, devido às características do meio e de incubação, já que essas são espécies estritamente anaeróbias e com maiores exigências nutricionais que o ágar Mitis Salivarius, o tioglicolato e o ágar Muller Hinton podem oferecer.

Algumas características bacterianas, como fatores de virulência, podem ser perdidas ou diminuídas com os sucessivos repiques, o que prejudicaria os resultados dos testes realizados in vitro para visualização do efeito inibitório das bacteriocinas.

Os resultados encontrados - constatação do efeito inibidor de cepas de estreptococos, sugestivo do grupo mutans, contra cepas de Streptococcus mutans - confirmam o conceito de Azevedo, Zelante e Ito (1985), de que o espectro de ação antibacteriano das bacteriocinas é limitado a espécies bastante afins às cepas produtoras, podendo até ser letais a si próprias.

O efeito antagônico modulador parece ser predominante no ecossistema oral dos portadores de Síndrome de Down, porém não inerente a eles, já que foram observados portadores de Síndrome de Down com elevados índices de cárie, durante a coleta.

A constatação de cepas presentes na microbiota oral de portadores de Síndrome de Down, que inibem o Streptococcus mutans, pode explicar a baixa prevalência de cárie nesses indivíduos, porém, apesar dos resultados positivos, ainda é discutível o papel de cepas produtoras de bacteriocinas na instalação e progressão da doença cárie. Testes devem ser feitos para a identificação dessa cepa e da substância produzida, o que poderá contribuir com informaçôes importantes, para novos experimentos que visem à prevenção da cárie. 


\section{CONCLUSÃO}

Como as microbiotas da placa dental e do sulco gengival são consideradas etiologicamente importantes no desenvolvimento da cárie e da doença periodontal, o melhor entendimento dos fenômenos inibitórios entre as bactérias que co-habitam esses nichos pode representar papel fundamental na instalação e progressão desses processos patológicos.

A descoberta de novas cepas, produtoras de substâncias antimicrobianas, contribuirá para o melhor entendimento do ecossistema oral, visando à prevenção e ao efetivo controle da cárie, justificando e estimulando a execução de novas investigações a respeito.

Mesmo com um resultado positivo, é discutível o papel das bacteriocinas em influenciar a ecologia microbiana, sendo necessárias observaçoos complementares, antes de se afirmar que a dinâmica da composição das diversas microbiotas humanas seja realmente modulada por essas substâncias.

\title{
Modulating action of microbiota of carriers of Down's syndrome on cariogenic microbiota
}

\begin{abstract}
Carriers of Down Syndrome have low prevalence of tooth decay, despite the fact that they show precarious oral hygiene. This research was carried out with the intent of evaluating the possible action of strains that produce bacteriocins as regulators of the carrier of Down Syndrome cariogenic microbiota. Streptococcus mutans and Streptococcus sobrinus are the main acid producers in the oral cavity. Consequently, they were tested antagonistically with strains isolated from the individuals with Down Syndrome in order to verify if cariogenic bacteria were being inhibited by the by the carrier's strains. Streptococcus mutans and Streptococcus sobrinus were isolated with the utilization of agar saccharose bacitracin medium and identified through standard biochemical tests. Samples of carriers'supragingival plaques were collected, spread through dissemination in Agar Mitis Salivarius and after isolation were cultivated in BHI liquid medium.10 cultures from syndromics were seeded in the Muller Hinton medium. After the growth, the colonies in the Petri dishes were treated by chloroform. Then, one portion of the cariogenic bacterium cultures was mixed with soft brain-heart infusion medium and immediately transferred to the Petri dish with the test cultures. Two of the ten tested strains presented a zone of inhibition against Streptococcus mutans. The discovery of strains that produce antibacterial substances may be responsible for the low prevalence of tooth decay in individuals with Down Syndrome. These findings may help to understand the relationship between oral microbiota and pathological tooth decay.
\end{abstract}

Keywords: Streptococcus mutans; Streptococcus sobrinus; Tooth decay - Down's syndrome; Bacteriocin.

\section{REFERÊNCIAS}

AMANO, A. et al. Periodontopathic bacteria in children with Down syndrome. J. Periodontol., Chicago, v.71, n.2, p.249-255, Feb. 2000.

AZEVEDO, R.V.P.; ZELANTE, F.; ITO,.I.Y. Detecção de cepas de Streptococcus mutans pro- dutoras de substâncias semelhantes a bacteriocina (mutacina). R. Fac. Odontol. Ribeirão Preto, Ribeirão Preto, v.22, n.2, p.6974, jul./dez.1985.

BALAKRISHNAN, M.; SIMMONDS, R.S.; TAGG, J.R. Diverse activity spectra of 
bacteriocin-like inhibitory substances having activity against Mutans Streptococci. Caries Res., Basel, v.35, p.75-80, 2001.

DAVEY, A.L.; ROGERS, A. H. Multiple types of the bacterium Streptococcus mutans_in the human mouth and their intra-family transmission. Arch. Oral Biol., Oxford, v.29, n.6, p.453-460, Nov. 1984.

FANTINATO, V.; JORGE, A.O.C.; SHIMIZU, M.T. Produção de substâncias inibidoras semelhantes a bacteriocinas por cepas de Streptococcus salivarius, isoladas da língua e garganta de crianças com e sem dor de garganta. R. Microbiol., São Paulo, v.30, n.4, p.332-334, out./dez.1999.

HÖFLING, J.F. et al. Presença de Streptococcus mutans e Streptococcus mutans associado a Streptococcus sobrinus em escolares de diferentes classes sócio-econômicas e sua relação com atividade cariogênica dessas populações. R. Odontol. Univ. São Paulo, São Paulo, v.13, n.2, p.173-180, abr./jun, 1999.

LIMA, F.L. et al. Bacteriocin production by Actinombacillus actinomycetemcomitans isolated from the oral cavity of humans with periodontal disease, periodontally healthy subjects and marmosets. Res. Microbiol., Paris, v.153, p.4552, 2002.
MORINUSHI, S.T.; LOPATIN, D.E.; TANAKA, $H$. The relationship between dental caries in the primary dentition and anti $S$. mutans serum antibodies in children with Down's syndrome. J. Clin. Pediatr., Dent., Birmingham, v.19, n.4, p.279-284, 1995.

PINAZO, J.D.C.; VIANNA, M.I.P. Cárie dentária e placa bacteriana em crianças de 07 a 14 anos portadores de Síndrome de Down, matriculadas em instituições públicas e privadas do município de Salvador-Bahia. R. Fac. Odontol. Univ. Fed. Bahia, Salvador, v.18/19, 1998/1999.

PINTO, U.G. Saúde bucal: odontologia social e preventiva. 2.ed. São Paulo: Santos, 1990.

SHAPIRA, J. et al. Caries level, Streptococcus mutans count, salivarius $\mathrm{pH}$, and periodontal treatment needs of adults Down syndrome patients. Spec. Care Dentist., Chicago, v.11, n.6, p.248-251, Nov./Dec. 1991.

SOET, J.J.; NYVAD, B.; KILIAN, M. Strainrelated acid production by oral streptococci. Caries Res., Basel, v.34, p.486-490, 2000.

TORTORA, G.J.; FUNKE, B.R.0; CASE, C.L. Microbiologia. 6.ed. Porto Alegre: ArtMed, 2000 .

\section{Agradecimentos}

Ivana Guerreiro Santos Pereira, Cirurgiã-dentista responsável pela clínica odontológica da Escola Especializada do SESI - Serviço Social da Indústria.

Recebido em / Received: 23/02/2005

Aceito em / Accepted: 13/06/2005 